\title{
Chromogranin A Cell Density as a Diagnostic Marker for Lymphocytic Colitis
}

\author{
Magdy El-Salhy $\cdot$ Doris Gundersen • \\ Jan G. Hatlebakk · Trygve Hausken
}

Received: 24 February 2012/ Accepted: 3 May 2012/Published online: 15 June 2012

(C) The Author(s) 2012. This article is published with open access at Springerlink.com

\begin{abstract}
Background Lymphocytic colitis (LC) can be mistakenly diagnosed as irritable bowel syndrome (IBS). In a previous study on IBS, some patients showed extremely high colonic chromogranin A cell density. Further examination of these patients showed that they suffered from LC.

Aims To investigate whether chromogranin A cell density is increased in LC patients and to examine the possibility of using this increase as a marker for the diagnosis of LC.

Methods Fifty-seven patients diagnosed with LC and 54 controls were included in the study. Biopsies from the right and left colon were obtained from both patients and controls, which were immunostained using the Avidin-biotin-complex method for chromogranin A, and cell density was quantified.

Results In both the right and left colon of patients with LC, the density of chromogranin A was significantly higher than in controls. This increase in chromogranin A cells occurs whether the number of these cells is expressed as number $/ \mathrm{mm}^{2}$ epithelium or as number/field. Chromogranin A cell density for the right and left colon expressed as number of cells $/ \mathrm{mm}^{2}$ epithelium or as cell number/field showed a high sensitivity and specificity as a diagnostic marker for LC.

Conclusions Chromogranin A is a common marker for endocrine cells, and the present finding suggests that
\end{abstract}

\footnotetext{
M. El-Salhy ( $₫)$

Section for Gastroenterology, Department of Medicine, Stord Helse-Fonna Hospital, Box 4000, 5409 Stord, Norway e-mail: magdy.el-salhy@helse-fonna.no

M. El-Salhy · J. G. Hatlebakk · T. Hausken

Section for Gastroenterology, Institute of Medicine,

University of Bergen, Bergen, Norway

D. Gundersen

Department of Research, Helse-Fonna, Haugesund, Norway
}

colonic hormones are involved in the pathophysiology of LC. The chromogranin cell density seems to be a good diagnostic marker with high sensitivity and specificity in both the right and left colon, thus sigmoidoscopy can be used in the diagnosis of LC using with this marker.

Keywords Diagnosis - Chromogranin A · Colon · Computer image analysis - Immunohistochemistry · Lymphocytic colitis

\section{Introduction}

Microscopic colitis (MC) is a chronic condition, which is characterized by watery diarrhea with normal radiologic and endoscopic findings. However, histopathological examinations of the colon reveal abnormal histology [1], which is of two distinctive types: lymphocytic colitis (LC) and collagenous colitis (CC) [1]. LC exhibits an increased number of colonic intra-epithelial lymphocytes $(>20 / 100$ epithelial cells), increased inflammatory cells within lamina propria, and preserved crypt architecture [1]. Population-based studies in Europe and in the United States have reported an incidence of LC ranging from 3.1 to 9.8 per 100,000 [2-10]. The prevalence of LC in Europe and the United States in population-based investigation has been found to be 14.2 per 100,000 population [2-9].

LC and irritable bowel syndrome (IBS) have similar symptoms and a normal endoscopic appearance, as well as normal radiologic findings [10, 11]. Several studies have shown that LC can be mistakenly diagnosed as IBS [12,13]. In a study on the colonic chromogranin A cell density in IBS patients [13], nine patients out of 50 showed extremely high colonic chromogranin A cell density [13]. This high density was in contrast to the low density of chromogranin cells in 
the rest of the IBS patients studied [13]. Further examination of these nine patients showed that they suffered from LC, although they fulfilled the Rome III criteria for IBS [13].

The symptoms of LC suggest an abnormally rapid intestinal motility and a decrease in the absorption of water. The neuroendocrine system of the gut plays a significant role in regulating gut motility, as well as the absorption of water and salts [14-17]. It is reasonable to assume, therefore, that colonic endocrine cells may be affected, and may be involved in the pathophysiology of this disorder. Chromogranin $\mathrm{A}$ is a $68-\mathrm{kDa}$ protein comprising 439 amino acid residues, which was isolated for the first time from secretory granules of the bovine adrenal medulla [18]. Chromogranin $\mathrm{A}$ is co-stored and co-released with monoamines and peptide hormones of the adrenal medulla, pituitary gland, parathyroid, thyroid C-cells, pancreatic islets, endocrine cells of the gastrointestinal tract, and sympathetic nerves [19-20]. Therefore, chromogranin A is considered to be a general marker for all endocrine cells.

The current study was undertaken to examine the colonic chromogranin cell density in a patient cohort with LC in order to establish whether a higher density of these cells occur, and to further examine the possibility of using colonic chromogranin A as a marker for the diagnosis of LC.

\section{Materials and Methods}

\section{Patients and Controls}

Fifty-seven patients diagnosed with LC during the period from 2007 to 2010 in all three hospitals of the Helse-Fonna region in western Norway, namely, Stord, Haugesund, and Odda hospitals, were included in this study. These patients included 41 females and 16 males, with an average age of 49 years (range 19-84 years). Fifty-four subjects that underwent colonoscopy with biopsies were used as controls. These subjects underwent colonoscopy because of gastrointestinal bleeding, where the source of bleeding was identified as hemorrhoids (26) and angiodysplasia (8), and a further 20 subjects were tested because of health worries caused by a relative being diagnosed with colon carcinoma. The control group was comprised of 38 females and 16 males, with an average age of 49 years (range 18-67 years).

The study was performed in accordance with the Declaration of Helsinki and was approved by the local Committee for Medical Research Ethics. All subjects gave oral and written consent.

\section{Colonoscopy}

Colonoscopy was performed in patients and controls and two biopsies were taken from the cecum, from both the ascending colon and the right half of the transverse colon. All biopsies were pooled together and used as right colon, regardless of gender. In addition, two biopsies were taken from the left half of transverse colon, from the descending colon, and from the sigmoid colon. These six biopsies were pooled together and used as left colon.

\section{Histopathology and Immunohistochemistry}

Biopsies were fixed in $4 \%$ buffered paraformaldehyde overnight, embedded in paraffin and cut into 5 - $\mu$ m-thick sections. The sections were stained by hematoxylin and eosin (H\&E) and immunostained with the avidin-biotincomplex (ABC) method using the Vectastain ABC-kit (Vector Laboratories) as described previously [21]. The primary antibody used was a monoclonal mouse anti-Nterminal of purified chromogranin A (DakoCytomation, code no. M869). The antibody was used at dilutions of $1: 1,500$. The second layer, biotinylated mouse anti-IgG was obtained from DakoCytomation. Negative and positive controls were the same as those described previously [21].

\section{Computerized Image Analysis}

The number of chromogranin A immunoreactive cells and the area of the epithelial cells was measured using Olympus software: Cell ${ }^{\wedge} \mathrm{D}$. When using $40 \times$ objectives, the frame (field) on the monitor represented an area of $0.14 \mathrm{~mm}^{2}$ of the tissue. Measurements were performed in ten randomly chosen fields for each individual. The immunostained sections of patients and controls were coded and mixed, and measurements were made without the knowledge of sections identity. The $40 \times$ objective was used. The data from fields were tabulated, the number of cells $/ \mathrm{mm}^{2}$ of epithelium was computed, and statistical analysis was performed automatically. The number of chromogranin A immunoreactive cells was also counted per microscopic field in 10 fields for each individual.

\section{Statistical Analysis}

As the results of controls and patients passed the normality test, the $t$ test was performed. $p<0.05$ was considered to be statistically significant.

\section{Results}

Endoscopy, Histopathology, and Immunohistochemistry

The colons of patients and control subjects were shown to be macroscopically normal. Histopathological examination of the colon biopsies from controls revealed normal 
histology and those from patients showed typical LC histopathology.

\section{Computerized Image Analysis}

The chromogranin A cell density in the right colon of the controls was $21.5 \pm 0.5$ per $\mathrm{mm}^{2}$ epithelium (mean $\pm \mathrm{SE}$ ), and in the left colon was $27.2 \pm 1.4$ per $\mathrm{mm}^{2}$ epithelium. Chromogranin A cell density was significantly higher in the right colon than in the left $(p=0.02)$. The number of chromogranin A cells per field in the right colon of controls was $9.3 \pm 0.5$ and in the left colon was $8.9 \pm 0.6$. There was no significant difference between right and left colon regarding the number of chromogranin A cells per field $(p=0.3)$. The chromogranin A cell density in the right colon of patients with $\mathrm{LC}$ was $68.8 \pm 4$ per $\mathrm{mm}^{2}$ epithelium, and in the left colon was $87 \pm 4$ per $\mathrm{mm}^{2}$ epithelium. The cell density of chromogranin A was higher in the left colon than in the right colon of patients with LC $(p=0.002)$. In patients with LC, the number of chromogranin A cells per field in the right colon was $38.7 \pm 2$

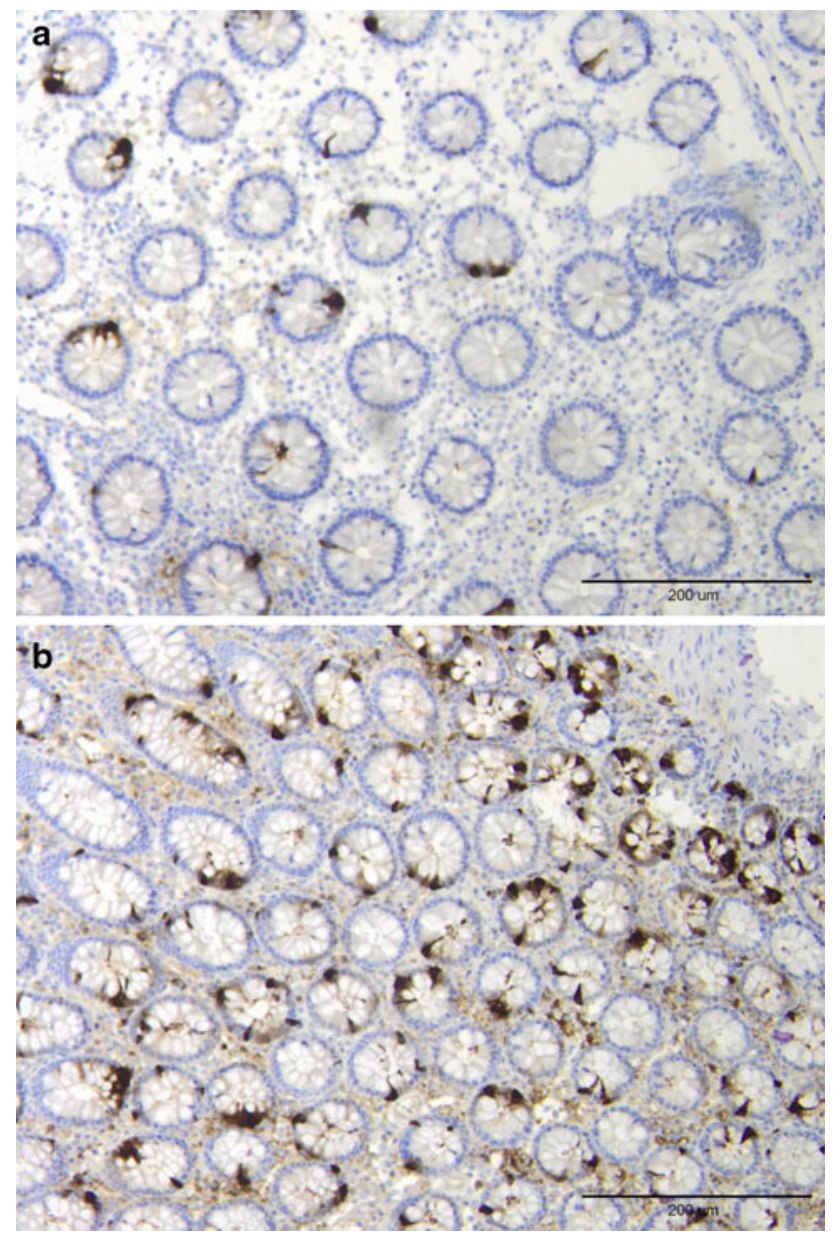

Fig. 1 Chromogranin A-immunoreactive cells in the colon of a control (a) and a patient with lymphocytic colitis (b) and in the left colon was $36.6 \pm 2$. There was no significant difference in the number of chromogranin A cells per field between right and left colon in patients with LC.

In both the right and left colon of patients with LC, the density of chromogranin A was significantly higher than in controls (Fig. 1). The increase in chromogranin A cells in patients with LC occurred whether the number of these cells was expressed as number $/ \mathrm{mm}^{2}$ epithelium or as number/field (Figs. 2, 3).

Receiver-operator characteristic (ROC) curves for chromogranin A cell density for the right and left colon show that in the right colon at a cut-off value of $>30$ cells $/ \mathrm{mm}^{2}$ epithelium, the sensitivity is $97 \%$ and specificity is $98 \%$. In the left colon, at a cut-off of $>29$ cells $/ \mathrm{mm}^{2}$ epithelium the sensitivity is $100 \%$ and specificity is $94 \%$ (Fig. 4).

ROC curves for chromogranin A cell number/field for the right colon shows that at a cut-off of $>15$ cells/field, the
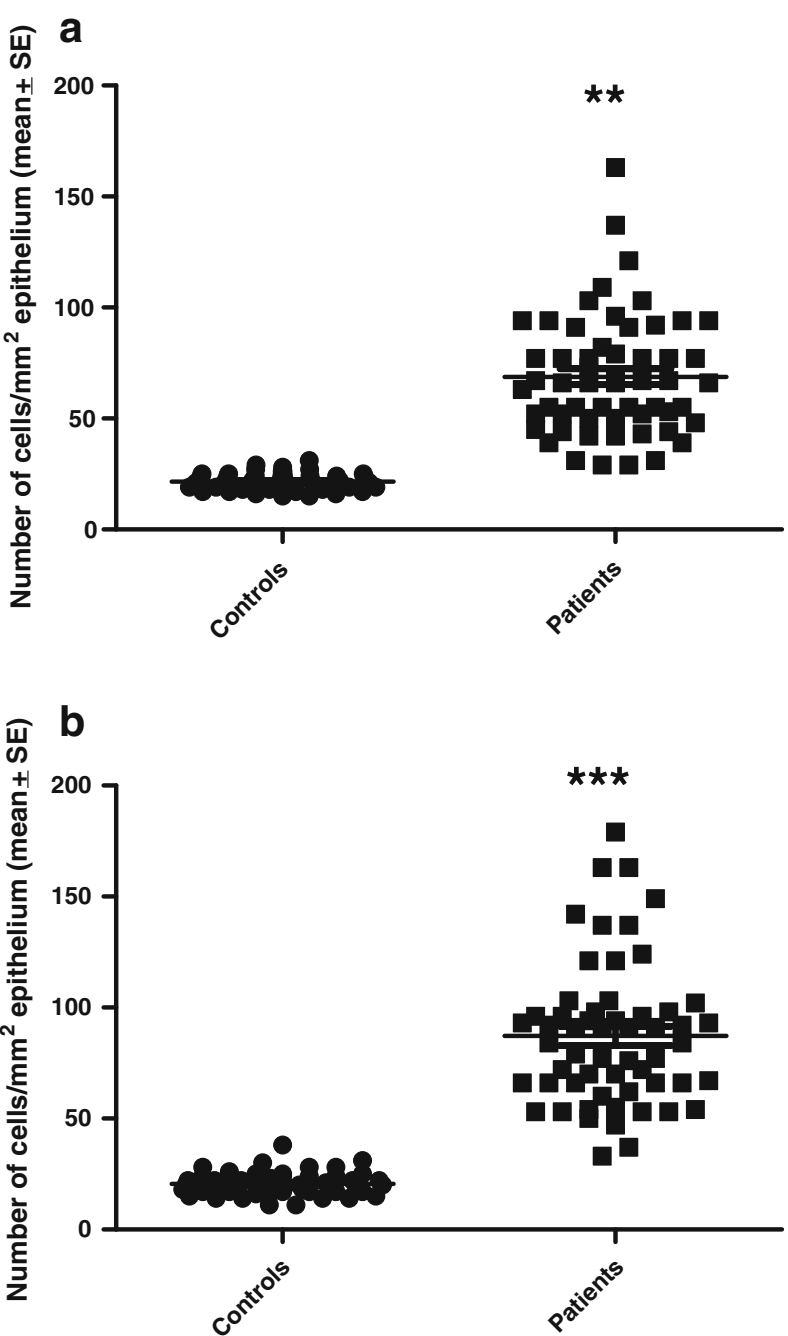

Fig. 2 Chromogranin A cell density in the controls and patients with lymphocytic colitis as expressed per $\mathrm{mm}^{2}$ epithelium: in the right colon (a) and left colon (b). **p $<0.01, * * * p<0.001$ 
sensitivity is $98 \%$ and specificity is $96 \%$. In the left colon, at cut-off values of $>15$ cells/field, the sensitivity is $93 \%$ and specificity is $89 \%$ (Fig. 5).

\section{Discussion}

The chromogranin A cell density was significantly higher in the right colon than in the left colon when the number of cells was counted with regards to epithelium cell numbers, but not when it was analyzed by microscopic field. In patients with LC, it was the opposite, where the left colon had a higher density of chromogranin cells. Again, there was no difference in chromogranin cell density between the right and left colon when the cells were analyzed per microscopic field. However, the significant difference obtained here could be a statistical type I error. The difference between the outcome when the number of chromogranin cells was compared to epithelium or microscopic field could be due the fact that chromogranin cells, which are situated among the epithelial cells, are more counted with regards to epithelium.

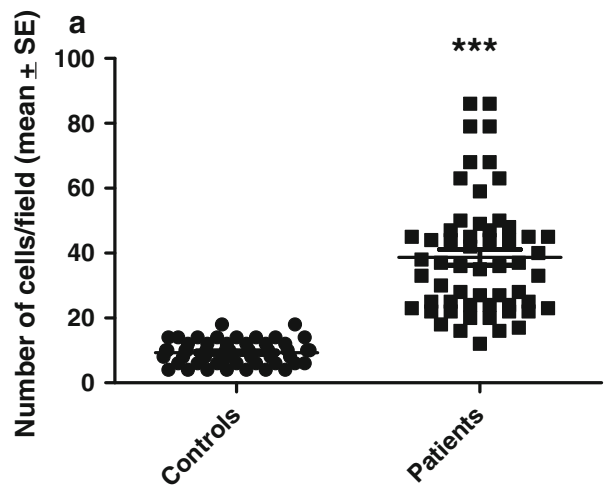

As chromogranin $\mathrm{A}$ is a common marker for endocrine cells, the current finding of a high density of colonic chromogranin A cells in patients with LC suggests that colonic hormones are involved in the pathophysiology of LC. Several studies present solid evidence for the interaction of the gut neuroendocrine peptides/amines and the local immune system in the gut. This is referred to as the endocrine/immune axis [22]. Thus, chromogranin-derived peptides, such as chromofugin and vasostatin-I, are able to penetrate into polymorphonuclear neutrophils, inducing an extracellular calcium entry [23]. This study illustrates the role of chromogranins in active communication between the neuroendocrine and immune system. Moreover, the chromogranin-derived peptide, catestatin stimulates chemotaxis of human peripheral blood monocytes [24, 25]. Secreoneurin, a chromogranin-derived peptide, reduces IL-6 release from eosinophils [26]. In addition, chromogranin-derived peptides modulate the endothelial permeability during inflammatory processes. Chromogranin A prevents the vascular leakage induced by the tumor necrosis factor (TNF)-alpha in a mouse model [26]. It is noteworthy that colonic chromogranin A cells have been

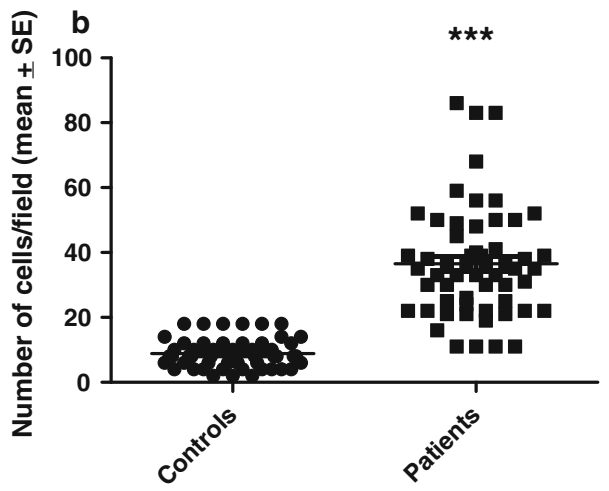

Fig. 3 Chromogranin A cell density expressed as he number of cells per field in controls and patients with lymphocytic colitis: in the right colon (a) and left colon (b). Symbols are the same as in Fig. 2
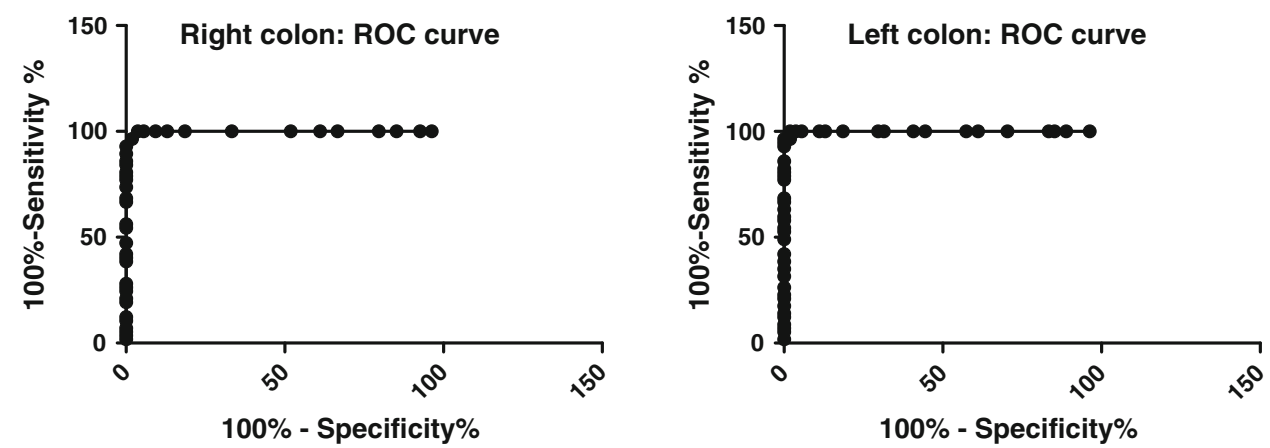

Fig. 4 Receiver-operator characteristic (ROC) curve for chromogranin A cell density for the right (a) and left colon expressed as number of cells $/ \mathrm{mm}^{2}$ epithelium (b) 

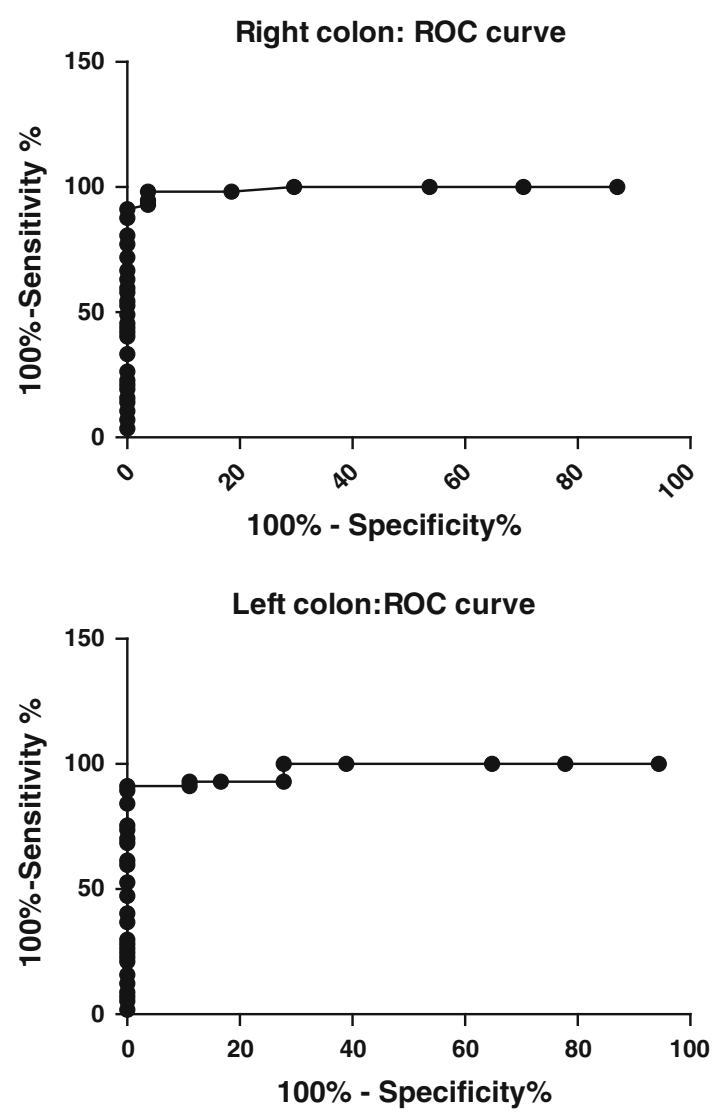

Fig. 5 ROC curve chromogranin A cell density in the right colon (a) and left colon (b), as expressed number of cells per field

found to increase in patients with ulcerative colitis (UC) and Crohn's disease (CD) [27]. Furthermore, elevated plasma and serum chromogranin levels have been reported in UC and CD patients [28, 29].

The chromogranin A cell density seems to be a good diagnostic marker with a high sensitivity and specificity. This was shown to be true whether biopsies were taken from the right or left colon. Furthermore, chromogranin A cell density showed the same high specificity and sensitivity when it was measured as number of cells per microscopic field. This facilitates the use of this marker even in small laboratories that are not equipped with computer image analysis facilities. The diagnosis of LC is based mainly on the finding of intraepithelial lymphocytosis. Lymphocytic infiltration has been reported, however, to occur more often in the right than in left colon [30]. In another study, biopsies taken from the left colon (sigmoid or descending colon) were enough to make the diagnosis in $98.6 \%$ of cases [30]. Thus, the reliability of using flexible sigmoidoscopy in making the diagnosis LC is not clear, and remains controversial. Chromogranin A cell density as a marker showed almost the same high sensitivity and specificity in biopsies taken from right or left colon, making sigmoidoscopy suitable for use with this marker.
Acknowledgments This study is supported by a grant from HelseFonna.

\section{Conflict of interest None.}

Open Access This article is distributed under the terms of the Creative Commons Attribution License which permits any use, distribution, and reproduction in any medium, provided the original author(s) and the source are credited.

\section{References}

1. Liszka L, Woszczyk D, Pajak J. Histopathological diagnosis of microscopic colitis. J Gastroenterol Hepatol. 2006;21:792-797.

2. Fernandez-Banares F, Salas A, Forne M, et al. Incidence of collagenous and lymphocytic colitis: a 5-year population-based study. Am J Gastroenterol. 1999;94:418-423.

3. Chande N, MacDonald JK, McDonald JW. Interventions for treating microscopic colitis: a Cochrane inflammatory bowel disease and functional bowel disorders review group systematic review of randomized trials. Am J Gastroenterol. 2009;104: 235-241.

4. Pardi DS, Kelly CP. Microscopic colitis. Gastroenterology. 2011;140:1155-1165.

5. Pardi DS. Microscopic colitis: an update. Inflamm Bowel Dis. 2004;10:860-870.

6. Yen EF, Pardi DS. Review article: microscopic colitis-lymphocytic, collagenous and mast cell colitis. Allment Pharmacol Ther. 2011;34:21-32.

7. Agnarsdottir M, Gunnlaugsson O, Orvar KB, et al. Collagenous and lymphocytic colitis in Iceland. Dig Dis Sci. 2002;47: $1122-1128$

8. Fernandez-Banares F, Forne M, Esteve M, et al. Collagenous colitis and lymphocytic colitis in Terrassa, Spain: an epidemilogical Study 1993-1996. Gastroenterology. 1997;122:A15.

9. Olesen M, Eriksson S, Bohr J, et al. Microscopic colitis: a common diarrheal disease. An epidemiological study in Örebro, Sweden, 1993-1998. Gut. 1995;37:394-397.

10. El-Salhy M, Halwe J, Lomholt-Beck B, Gundersen D. The prevalence of inflammatory bowel diseases and microscopic colitis and colorectal cancer in patients with irritable bowel syndrome. Gastroenterol Insights. 2011;3:7-10. doi:10.4081/ gi.2011.e3.

11. El-Salhy M, Gundersen D, Hatlebakk JG, Hausken T. Irritable bowel syndrome. New York: Nova Science Publisher; 2012.

12. El-Salhy M, Lomholt-Beck B, Hausken T. Chromogranin as a tool in the diagnosis of irritable bowel syndrome. Scan J Gastroenterol. 2010;45:1435-1439.

13. El-Salhy M, Lomholt-Beck B, Gundersen D. High chromgranin A cell density in the colon of patients with lymphocytic colitis. Mol Med Rep. 2011;4:603-605.

14. Goya PK. Hirano I mechanisms of disease: the enteric nervous system. N Engl J Med. 1996;334:1106-1615.

15. McConalouge K, Furness JB. Gastrointestinal neurotransmitters. Baillieres Clin Endocrinol Metab. 1994;8:51-76.

16. Debas HT, Mulvihill SJ. Neuroendocrine design of the gut. Am J Surg. 1991;161:243-249.

17. El-Salhy M. Gut neuroendocrine system in diabetes gastroenteropathy: possible role in pathophysiology and clinical implications. In: Ashley M, ed. Focus on Diabetes Research. New York: Nova Science Publisher; 2006:79-102.

18. Taupenot L, Harper KL, O'Connor DT. The chromograninsecretogranin family. $N$ Engl J Med. 2003;348:1134-1149. 
19. Wicdenmann B, Huttner WB. Synaptophysin and chromogranin/ secretogranins-widespread constituents of distinct types of neuroendocrine vesicales and new tools in tumor diagnosis. Virchows Arch B Cell Pathol. 1989;58:95-121.

20. Deftos LJ. Chromogranin A: its role in endocrine function and as an endocrine and neuroendocrine tumor marker. Endocr Rev. 1991;12:181-188.

21. El-Salhy M, Sandsrøm E, Nästrøm E, et al. Application of computer image analysis in endocrine cell quantification. Histochemical J. 1997;29:249-256.

22. Khan WI, Ghia JE. Gut hormones: emerging role in immune activation and inflammation. Clin Exp Immunol. 2010;161:19-27.

23. Zhang D, Shooshtarizadeh P, Laventie BJ, et al. Two chromogranin a-derived peptides induce calcium entry in human neutrophils by calmodulin-regulated calcium independent phospholipase $\mathrm{A}_{2}$. PLOS ONE. 2009;4:e4501.

24. Egger M, Beer AG, Theurl L, et al. Monocyte migration: a novel effect and signaling pathway of catestatin. Eur J Pharmacol. 2008;598:104-111.
25. Feistritzer C, Mosheimer BA, Colleselli D, Wiedermann CI, Kahler CM. Effects of the neuropeptide secretoneurin on natural kill cell migration and cytokine release. Regul Pept. 2005;126: 195-201.

26. Ferrero E, Magni E, Curnis F, Villa A, Ferrro ME, Corti A. Regulation of endothelial cells barrier function by chromogranin A. Ann NY Acad Sci. 2002;971:355-358.

27. El-Salhy M, Danielsson Å, Stenling R, Grimelius L. Colonic endocrine cells in inflammatory bowel disease. J Int Med. 1997;242: 413-419.

28. Sciola V, Maaironi S, Conte D, et al. Plasmachromogranin A in patients with inflammatory bowel disease. Inflamm Bowel Dis. 2009;15:867-871.

29. Sidhu R, Drew K, Lobo AJ. Elevated serum chromogranin A in irritable bowel syndrome (IBS) and inflammatory bowel disease (IBD): A shared model for pathogenesis? Inflamm Bowel Dis. 2010;16:361.

30. Yen EF, Pardi DS. Review of the microscopic colitis. Curr Gastroenterol Rep. 2011;13:458-462. 